\title{
PLACE BRANDING SUMEDANG SEBAGAI PUSEUR BUDAYA SUNDA
}

Anton Pramono ${ }^{a}$, Hanny Hafiar, Lilis Puspitasari

Program Studi Hubungan Masyarakat, Fakultas Ilmu Komunikasi, Universitas Padjadjaran

\begin{abstract}
The purpose of this study is to describe how Sumedang government build Sumedang as the center of Sundanese culture through Place Branding that includes the process of conducting SWOT analysis, Creating Brand Vision, Setting Program Goals and benchmarks, Implementing Brand Vision, and Brand Equity Evaluation. This research uses descriptive research method. Technique of collecting data of in-depth interview, observation and literature study. In this research concludes that: Sumedang government in conducting SWOT analysis there are room for improvement, in creating brand vision SPBS has taken into account the organization culture, identity, and government vision and mission but the brand vision are not articulated enough for the stakeholder as diferent meaning are comprehended, on setting program goals and benchmarks, the program goals are not articulated enough as the goals are to major and have no milestones which relatively easier to achieve, the benchmarks used by the government is also not detail enough which in return couldn't give the governement best practices ideas for managing SPBS. In implementing brand vision, the government didn't implement evaluation in order to response the distress in their internal body, on the external campaign program there are much area to be explored such as using PR surrogates as storyteller in telling the brand story and better management in social media., and then minimum qualifications for communcation staff of SPBS has to be made. Lastly, on brand equity evaluation there are room for improvement such as utilizing financial and consumer based evaluation to balance the image and substance of Place Branding.
\end{abstract}

Keywords

Place Branding, Place Branding Building Process, Sumedang Government, Sundanese Culture

a antonjpramono@gmail.com 


\section{PENDAHULUAN}

Pemerintah Kabupaten Sumedang sebagai salah satu unsur pemerintah daerah mencoba menggulirkan suatu kebijakan mengenai budaya yang dapat menunjang sektor pembangunan kedaerahan yaitu kebijakan Place Branding Sumedang puseur Budaya Sunda sebagai upaya untuk bersaing dan beradaptasi terhadap perubahan yang dihadapi Kabupaten Sumedang.

Selain itu, alasan lainnya yang mendasari upaya Place Branding Sumedang puseur budaya Sunda adalah budaya tradisional Sunda yang masih dipegang teguh dalam kehidupan bermasyarakat di Sumedang. Seperti yang diungkapkan dalam pernyataan budayawan Cece Saipudin:

"Salah satu alasan Sumedang memproklamirkan diri sebagai puseur budaya Sunda adalah karena masyarakat Sumedang masih memegang teguh budaya tradisional Sunda dalam menjalankan kehidupan. Misalnya upacara bercocok anam dalam tarawangsa, upacara sunatan lahir kesenian dog-dog, kuda renggong dan masih banyak lagi. Lalu, dari segi budaya yang lainnya seperti goong renteng, tari umbul, tayuban, bangreng dan yang lain."

Pemerintah Kabupaten Sumedang melihat potensi dari segi budaya tersebut dapat dimanfaatkan sebagai sebuah nilai yang mencirikan Kabupaten Sumedang karena itu lahirlah Peraturan Bupati Sumedang Nomor 113 Tahun 2009 Tentang Sumedang Puseur Budaya Sunda (SPBS). Adapun indikator dari Place Branding SPBS meliputi beberapa bentuk seperti wujud gagasan, wujud perilaku, hingga wujud karya. Seperti yang diungkapkan Ade Rohana sebagai Kepala Bidang Kebudayaan Disparpora Kabupaten Sumedang selanjutnya:

"Adapun indikator yang mendasarkan budaya seperti apa yang menjadi produk daerah yaitu basis citra budaya daerah yang diturunkan dalam bentuk wujud karya, gagasan, serta wujud perilaku."

Wujud gagasan di antaranya diturunkan dalam bentuk kebijakan inventarisasi dan penggalian sejarah naskah kono, pendokumentasian serta perumusan strategi dan diseminasi pengembangan adat istiadat dan nilai sosial budaya Sunda di Kabupaten Sumedang lalu perilaku diturunkan menjadi kebijakan pemeliharan sastra, bahasa, dan aksara Sundan penyusunan dan pelaksanaan Standar Operasional Prosedur (SOP) pelayanan publik berbasis budaya Sunda; pengembangan bahan ajar muatan lokal berbasis budaya.

Namun dari hasil pra riset yang dilakukan oleh peneliti, rasa Pusat Budaya Sunda belum terlalu tampak. H. Toto Prijatman, salah seorang pupuhu atau pemangku adat di Sumedang, menyatakan bahwa nilai SPBS belum terlalu tampak karena belum terlalu melibatkan budayawan sehingga masih gagal dalam menyerap esensi Sumedang sebagai Puseur Budaya Sunda.

Tujuan utama program SPBS yaitu untuk memperkuat jatidiri aparatur dan warga masyarakat diturunkan ke dalam tujuan minor pembangunan secara fisik dan pelaksananan kegiatan berbentuk acara untuk nonfisik dan dalam pelaksanaannya tujuan ini berjalan sesuai rencana. Pemasukan dari sektor tersebut hanya mencapai 1 Miliar dalam periode 2013-2017 seperti yang diungkapkan oleh pernyataan berikut.

"Selain itu dalam menentukan tujuan serta tolok ukur dalam perancangan program SPBS pemerintah belum menerapkan tolok ukur yang jelas dalam salah satu indikatornya seperti diungkapkan dalam pernyataan berikut:

"Untuk tujuan penguatan jatidiri aparatur dan warga masyarakat tolok ukurnya dari pembangunan periode sebelumnya dan mengacu ke grand 
plan SPBS yang dirumuskan dari awal, sedangkan untuk variabel PDB sektorpariwisata melalui mufakat dan diputuskan dalam musyawarah awal periode"

Dalam tahap selanjutnya, upaya pengkomunikasian program SPBS ditempuh melalui berbagai saluran. Salah satunya dengan pembangunan infrastuktur yang mencirikan nilai-nilai SPBS. Contohnya adalah pembangunan Bundaran Binokasih, Pengondisian Alun-Alun Sumedang, Renovasi peninggalan purbakala serta petilasan-petilasan budaya serta perbaikan fasilitas pendukung. Selanjutnya, pemkab Sumedang belum menerapkan evaluasi serta implementasi dalam perancangan program SPBS secara khusus dan hanya menggunakan monitoring media sebagai bentuk evaluasi program SPBS.

"Untuk mengukur keberhasilan program SPBS kita lihat dari penerimaan yang ada di masyarakat dan daerah, salah satu caranya lewat media monitoring pada media cetak terkait pelaksanaan kegiatan SPBS seperti pembangunan atau acaraacara, jika bernada positif maka kami nilai berhasil dan jika negatif kami rancang langkah terkait entah berupa klarifikasi atau rilis"

Namun bentuk evaluasi melalui media monitoring tersebut belum bisa mengatasi permasalahan yang lebih praktis seperti dalam tidak tercapainya tujuan PDB sektor pariwisata sebesar 2 Miliar seperti yang diungkapkan dalam pernyataan berikut:

Salah satu indicator Place Branding ini yang tidak tecapai adalah target pemasukan dari sektor pariwisata senilai 2 Miliar tidak tercapai. Pemkab Sumedang mengatakan karena sumber daya yang kurang mumpuni untuk evaluasi dan pengawasan, maka mereka memutuskan untuk menurunkan target. $^{2} \mathrm{Hal}$ ini menunjukan bahwa Place Branding SPBS belum berhasil karena tidak mencapai salah satu target programnya.

Dari fakta di atas diketahui berbagai permasalahan dalam observasi awal bahwa pelaksananan Place Branding Sumedang puseur Budaya Sunda belum sesuai dengan konsep Place Branding yang meliputi pelaksanaan analisa SWOT, penciptaan brand vision, penentuan program goals dan benchmarks, implementasi brand vision, serta evaluasi brand yang dikemukakan oleh Staci Zavattaro dalam buku Place Branding Through Phases of the Image. Untuk itu penulis tertarik untuk meneliti topik tersebut, yakni bagaimana Place Branding Kabupaten Sumedang sebagai Pusat Budaya Sunda yang dijalankan oleh Pemerintah Kabupaten Sumedang.

\section{METODOLOGI PENELITIAN}

Penelitian ini menggunakan paradigma positivisme. Peneliti menggunakan paradigma positivisme dalam penelitian dikarenakan peneliti ingin mengetahui proses Place Branding Sumedang Sebagai Puseur Budaya Sunda. yang dilakukan oleh Pemerintah Kabupaten Sumedang. Penelitian dilakukan bukan untuk menguji teori, sehingga konsep atau model yang digunakan hanya dijadikan guide dalam menentukan pertanyaan penelitian. Sedangkan metode yang digunakan dalam penelitian ini adalah metode deskriptif. Berikut bagan dari tahapan analisis SWOT Sumedang puseur Budaya Sunda

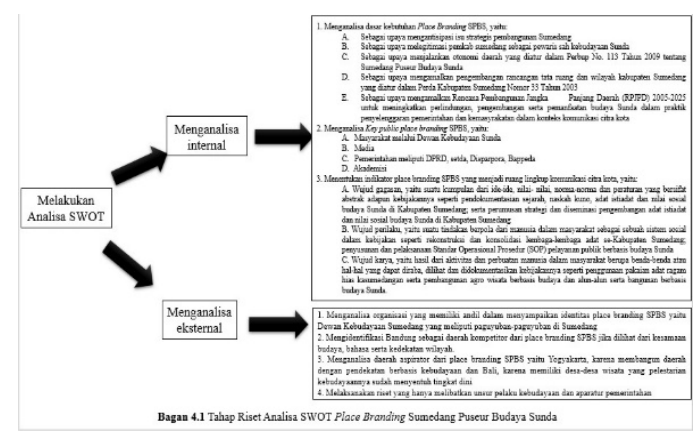

Gambar 1. Analisa SWOT Place Branding Sumedang Puseur Budaya Sunda

${ }^{2}$ Ibid. 
Langkah pertama Pemkab Sumedang dalam melakukan analisa internal adalah mengetahui dasar kebutuhan dicetuskannya Place Branding Sumedang sebagai Puseur Budaya Sunda. Kebijakan SPBS dianggap penting mengingat adanya isu-isu strategis mengenai pembangunan di Sumedang, seperti pembangunan bandara dan waduk. Pertimbangan lain digulirkannya kebijakan tersebut adalah nilai historis yang dimiliki oleh Kabupaten Sumedang yang merupakan penerima Mahkota Binokasih dari Kerajaan Padjadjaran. Setelah itu, Pemkab Sumedang kemudian mengidentifikasi target publik (key public) dari program ini. Menurut hasil wawancara dengan narasumber, maka target publik dari kampanye ini terdiri dari masyarakat melalui perwakilan Dewan Kebudayaan Sunda, media, akademisi, serta pemerintahan yang meliputi DPRD, Bappeda, Setda Sumedang hingga Disparpora.

Riset Key Public yang dilakukan oleh Pemkab Sumedang belum terlalu optimal. RIset Target Publik dalam sebuah proses Place Branding seharus melibatkan seluruh elemen pemerintahan yang ada di Kabupaten Sumedang dan meneliti setiap komunikasi yang mereka lakukan terkait SPBS.

Dalam analisa Internal, Pemkab Sumedang juga memetakan indikator nyata dari Place Branding Sumedang yang menjadi ruang lingkup komunikasi citra kota. Indikator tersebut terdiri dari wujud gagasan yang berupa kumpulan dari ide-ide, nilai- nilai, norma-norma dan peraturan yang bersifat abstrak adapun kebijakannya seperti pendokumentasian sejarah, naskah kuno, adat istiadat dan nilai sosial budaya. Lalu wujud perilaku, yaitu suatu tindakan berpola dari manusia dalam masyarakat sebagai sebuah sistem sosial dalam kebijakan seperti rekonstruksi dan konsolidasi lembaga-lembaga adat se-Kabupaten Sumedang; penyusunan dan pelaksanaan Standar Operasional Prosedur (SOP) pelayanan publik berbasis budaya Sunda. Upaya penentuan indikator ini telah sesuai dengan rekomendasi karena mencoba untuk mengidentifikasi serta mengartikulasikan bentuk yang tentuya memudahkan proses selanjutnya yaitu rancangan brand vision. (Mathieu:2005).

Selain melakukan analisa internal, diperlukan juga dilakukan analisa eksternal untuk mengidentifikasi peluang dan ancaman dari pihak luar. Analisa eksternal sejatinya berfungsi untuk mengidentifikasi stakeholder primer, social networks, dan organisasi lainnya yang memiliki peran untuk menyampaikan pesan daerah (Goldhaber \& Krivonos, 1977). Upaya yang dilakukan oleh Pemkab Sumedang cukup memberikan gambaran tentang stakeholder primernya yaitu masyarakat serta pemerintahan dan organisasi pendukung yaitu Dewan Kebudayaan Sumedang.

Menurut narasumber, organisasi yang berkaitan dengan program Place Branding SPBS ini adalah paguyuban-paguyuban yang ada di tingkat desa, kelurahan, hingga kecamatan yang tergabung dalam Dewan Kebudayaan Sumedang. Akan tetapi, stakeholder ini masih terlalu luas dan belum dipetakan lebih rinci, mengingat tujuan dari program Place Branding ini adalah meningkatkan daya saing Sumedang yang tentunya dalam skala nasional maupun internasional. Untuk analisa kompetitior, Pemkab Sumedang menganggap Bandung salah satu saingan terdekat secara geografis dan juga secara nilai-nilai kebudayaan. Lalu untuk kota yang dijadikan benchmark adalah kota Yogyakarta dan Bali. Kedua kota itu dipilih karena kedua kota itu punya nilai-nilai kebudayaan dan melakukan branding dengan nilai kebudayaan. Masyarakat kedua kota itu juga konsisten mengimplementasikan nilainilai tersebut sejak usia dini. Kemudian, yang terakhir adalah pelaksanaan riset mengenai program Place Branding. Pemkab Sumedang memberikan keterangan bahwa para paguyuban-paguyuban memerlukan adanya program SPBS akan tetapi riset ini hanya melibatkan unsur pelaku kebudayaan dan aparatur pemerintahan. Peneliti melihat jawaban ini sama sekali tidak memberikan gambaran mengenai tingkat brand equity dari 
para stakeolder, yaitu awareness, association, quality, and loyalty (Aaker, 1997).

Rekomendasi lainnya dalam perancangan analisa SWOT adalah dengan melakukan analisis prasyarat mendasar seperti sumber daya yang ada di kota, kapabilitas kota, peluang untuk tumbuh serta identitas. Selain itu, seharusnya setelah diadakan riset internal dan eksternal dilaksanakan pula pembandingan. Pertama, praktisi menganalisa kekuatan internal hingga mendorong kekuatan tersebut menjadi keuntungan kompetitif dan membangun kepercayaan secara internal dan eksternal. Kedua, kelemahan internal diidentifikasi dan dilakukan perbaikan yang tentunya bergantung pada kapabilitas organisasi pula. Ketiga, kesempatan serta ancaman eksternal harus dievaluasi demi melihat apakah kapabilitas internal mampu menyembuhkan atau memperkeruh situasi eksternal. (Zavattaro, 2014: 129).

Lalu pada tahap selanjutnya yaitu proses penciptaan brand vision atau visi mereka terkait Place Branding SPBS. Menurut Zavattaro (2014:122) ada dua langkah yang harus ditempuh dalam proses penciptaan brand vision ini, yaitu (1) mengidentifikasi core value dari organisasi, dan (2) menciptakan brand vision, yaitu pertama, target audience kedua, external customernya dan strategi renaming serta bagaimana CGV Cinemas melakukan rebranding marketing plan. Internal customer adalah communication campaign serta pelatihan yang sesuai dengan kebijakan dan prosedur perusahaan.

Gambar 2 berikut adalah bagan tahapan pembuatan Brand Vision dari Sumedang sebagai puseur Budaya Sunda. Poin pertama dalam penciptaan brand vision atau visi merek adalah identify core value atau mengidentifikasi nilai inti. Tujuan dari identifikasi nilai inti adalah untuk memberikan gambaran dalam menciptakan nilai inti yang mampu melibatkan budaya serta nilai-nilai yang dianut oleh organisasi

Dari hasil wawancara yang peneliti

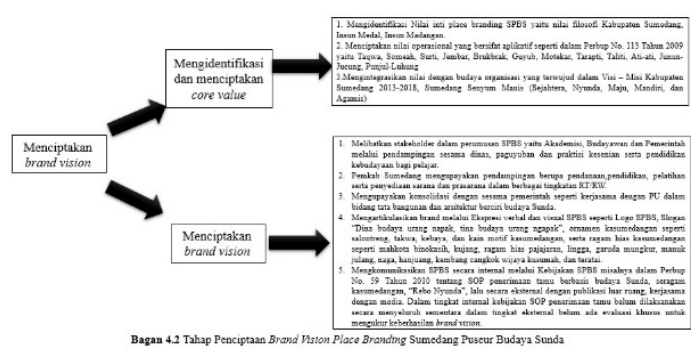

Bagan 2 Tahapan menciptakan Brand Vision Sumedang Puseur Budaya Sunda

lakukan terhadap narasumber, pihak pemkab telah mengidentifikasi nilai-nilai inti dari pemrograman SPBS melalui nilai yang terbagi ke dalam beberapa jenis, seperti nilai filosofi Insun Medal, Insun Madangan yang merupakan nilai yang tersemat di Kabupaten Sumedang melalui motto daerah. Nilai tersebut kemudian diturunkan menjadi nilai yang lebih aplikatif atau operasional yaitu nilai-nilai seperti Taqwa, Someah, Surti, Jembar, Brukbrak, Guyub, Motekar, Tarapti, Taliti, Ati-ati, Junun-Jucung, Punjul-Luhung yang merupakan nilai yang tertera pada Perbup No. 113 Tahun 2009.

Pada tahap selanjutnya, tahap penciptaan nilai inti memiliki tujuan untuk menciptakan dasar bagi perancangan langkah selanjutnya dalam program Place Branding. Dalam perancangan program SPBS, Pemkab Sumedang turut melibatkan Akademisi, Budayawan dan Pemerintah berdasarkan hasil pernyataan dalam wawancara. Apa yang dilakukan oleh pemkab Sumedang telah sesuai dengan rekomendasi yang ada karena itu kualitas kepemimpian Pemkab Sumedang dalam SPBS dinilai cukup baik karena telah mengayomi dan mendampingi sesama dinas, paguyuban dan praktisi kesenian melalui Dewan kebudayaan Sunda serta pelajar melalui pendidikan kebudayaan sebagai upaya mengedukasi stakeholder terkait nilai inti SPBS (Zavattaro, 2014: 133). 
Selanjutnya dalam upaya mengkomunikasikan program SPBS tentu perlu media untuk menyampaikannya. Ekspresi verbal dan visual SPBS seperti Logo SPBS, Slogan "Dina budaya urang napak, tina budaya urang ngapak", ornamen kasumedangan seperti salontreng, takwa, kebaya, dan kain motif kasumedangan, serta ragam hias kasumedangan seperti mahkota binokasih, kujang, ragam hias pajajaran, lingga, garuda mungkur, manuk julang, naga, hanjuang, kembang cangkok wijaya kusumah, dan teratai.

Dalam penciptaan brand vision, kerap kali visi yang unik dan khaslah yang pada akhirnya paling melekat dalam benak stakeholder, selain itu visi yang jelas dan tidak berbelit-belit pun menjadi rekomendasi dalam penciptaan brand vision seperti yang diungkapkan Bapak Boy Syahbana, triangulator penelitian ini dalam pernyataan berikut:

"Visi itu bentuknya mengikat dan tentunya sangat penting seakan-akan menjadi koridor untuk jalannya pembangunan kota, saran simpelnya visi yang bagus adalah visi yang unik dan memberikan ciri khas pada kota itu, Sumedang puseur budaya Sunda menilai diri mereka unik namun belum mampu membangun kekhasan dari brandingnya sehingga tidak tertanam kuat di benak stakeholder, mungkin karena visinya sendiri yang berbelit-belit." ${ }^{3}$

Tahap berikutnya dalam proses Place Branding Sumedang adalah Penentuan Brand Goals dan Benchmarks. Menurut Zavattaro (2014:122) ada dua langkah yang harus ditempuh dalam proses penentuan brand goals dan benchmarks ini, yaitu (1) set program goals, dan (2) establish benchmarks. Adapun untuk langkah pertama yaitu menentukan program goals atau tujuan program adalah dengan

\footnotetext{
${ }^{3}$ Hasil Wawacara Triangulator, Boy Syahbana, selaku Senior Consultant Makna Informasi, 22 Mei 2018
}

menentukan capaian program terlebih dahulu.

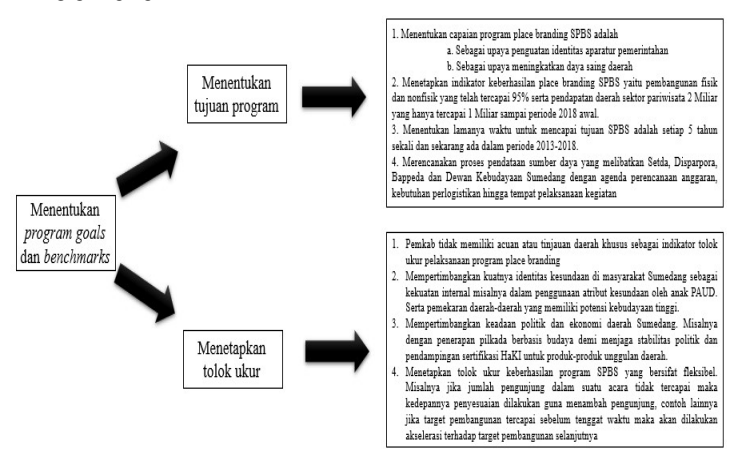

Gambar 3. Proses Penentuan Goals dan Benchmarks SPBS

Dalam penentuan Goals dari program SPBS ini, peneliti menilai bahwa tujuan ini kurang spesifik. Menurut George T. Doran (1981), pembuatan tujuan harus memenuhi kaidah SMART yang terdiri dari Specific (simple, sensible, significant), Measurable (meaningful, motivating, Achievable (agreed, attainable), Relevant (reasonable, realistic and resourced, results-based), Time bound (time-based, time limited, time/cost limited, timely, time-sensitive). pemkab Sumedang belum mengaplikasikan aspek achievable karena dasar penentuan target pemasukan sebesar 2 Miliar tidak memiliki benchmarks yang jelas. Saran peneliti lainnya dalam menentukan tujuan adalah pembuatan indikator yang lebih fleksibel. Misalnya jika jumlah pengunjung dalam suatu acara tidak tercapai maka kedepannya penyesuaian dilakukan guna menambah pengunjung, contoh lainnya jika target pembangunan tercapai sebelum tenggat waktu maka akan dilakukan akselerasi terhadap target pembangunan selanjutnya. Hal ini telah sesuai dengan konsep fleksibilitas bagi organisasi yang direkomendasikan oleh Zavattaro (2014:137)

Setelah menentukan tujuan program maka langkah selanjutnya adalah menentukan benchmarks atau tolok ukur. Berdasarkan hasil wawancara pemkab 
Sumedang tidak memiliki acuan atau tinjauan daerah khusus yang menjadi tolok ukur keberhasilan program SPBS dan tentunya praktek ini belum sesuai dengan rekomendasi. Saran peneliti dalam menentukan benchmarks apa yang kita tawarkan sesuai dengan kebutuhan dalam kompetisi, memperhitungkan area pengembangan benchmarks itu sendiri, serta tolok ukur yang seimbang antara kebutuhan internal dan eksternal (Reynolds \& Philips, 2005).

Tahapan berikutnya dalam proses Place Branding adalah Pada sub-bab ini peneliti akan menjabarkan bagaimana proses implementasi brand vision atau visi merek dari Place Branding SPBS. Menurut Zavattaro (2014:122) ada tiga langkah yang harus ditempuh dalam proses implementasi brand vision ini, yaitu (1) brand communication,(2) brand expansion, dan (3) logistik.

Pada langkah pertama yaitu brand communication atau komunikasi merek hal yang harus diperhatikan adalah bentuk pengkomunikasian dari program itu sendiri. Bentuk pengkomunikasian dari SPBS terbagi menjadi dua primer dan sekunder, untuk

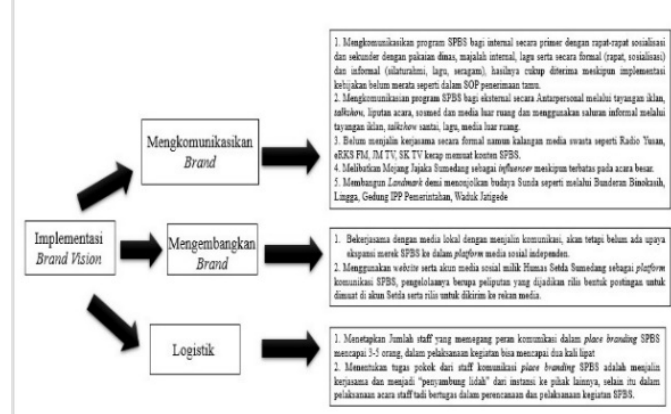

Gambar 4. Proses Implementasi Brand Vision dalam Place Branding SPBS

primer contohnya lewat komunikasi langsung seperti dalam rapat-rapat formal sosialisasi kebijakan, lalu bentuk sekundernya dengan menggunakan media seperti lagu, lalu pakaian dinas yang menampilkan nilai SPBS.

Selanjutnya untuk jenis saluran komunikasi yang digunakan dalam ranah internal SPBS adalah secara formal dan informal, saluran formal seperti rapat koordinasi atau sosialisasi nilai-nilai SPBS seperti dalam Perbup No.59 Tahun 2010 tentang SOP penerimaan tamu, selanjutnya untuk contoh informal misalnya dengan silaturahmi atau kunjungan kerja ke pihak terkait, selain itu penggunaan lagu pun menjadi salah satu cara mengkomunikasikan di pihak internal.

Upaya pengkomunikasian internal yang dilakukan pemkab sebetulnya tidak hanya melibatkan aparatur pemerintahan saja, program pendidikan dan pendampingan di tingkat sekolah serta kelompok seni yang ada pada tingkat desa dan kecamatan pun turut dilakukan oleh Pemkab.

Selanjutnya dalam upaya pengkomunikasian pada pihak eksternal pemkab Sumedang cenderung menggunakan bentuk komunikasi antarpersonal melalui media tayangan-tayangan pada televisi swasta atau menggunakan himbauan berbentuk talkshow pada radio, selain itu pemkab pun menggunakan komunikasi luar ruang seperti spanduk atau baligo. Selain itu website serta sosmed pun digunakan dalam memuat publikasi kegiatan SPBS. Untuk saluran yang digunakan dalam pengkomunikasian kepada pihak eksternal, Pemkab Sumedang cenderung menggunakan saluran informal seperti dalam liputan kegiatan atau talkshow yang sifatnya santai.

Pemkab Sumedang belum mampu menciptakan brand story yang lebih mengikat dan membantu narasi citra kota. Dalam menciptakan informasi yang mampu menggapai banyak orang, praktisi diharuskan untuk membangun cerita melalui media yang ada (Gover, 2013). Untuk menawarkan informasi yang mampu mencapai banyak orang, praktisi dapat menampilkan brand story dalam website dan membangun forum komunitas yang menawarkan perkenalan serta pemahaman dari apa yang mendasari strategi branding jika sumber daya mencukupi. 
Salah satu kekurangan terbesar dalam perancangan komunikasi eksternal ini adalah minimnya strategi yang komprehensif serta menyasar target eksternal yang terfokus, hal inilah yang berkontribusi besar terhadap tidak tercapainya salah satu indikator keberhasilan program SPBS yaitu PDB sebesar 2 Miliar pada periode 2013-2018. Hal ini dipengaruhi pula oleh analisa eksternal yang tidak merinci key public secara detail. (Zavattaro, 2014:129). Selanjutnya dalam praktek media relations pun pemkab Sumedang tidak menjalin kerjasama secara formal meskipun beberapa media lokal kerap memuat pemberitaaan pemkab Sumedang. Dalam pelaksanaannya selama ini strategi yang dilakukan bersifat spontan sehingga tidak ada perancangan tujuan untuk jangka pendek apalagi jangka panjang.

Langkah selanjutnya dalam implementasi brand vision adalah brand expansion atau ekspansi merek. Brand expansion sendiri adalah kesempatan untuk meningkatkan brand equity dengan mengekpansi makna dari brand tanpa meninggalkan ciri kebudayaan, semiotika, dan nilai sosialnya (Spiggle, et. al., 2012:967).

Dalam pelaksanaanya, pemkab Sumedang sendiri belum memiliki upaya mengekspansi merek SPBS ke dalam platform media independen, adapun ekspansi yang dilakukan berupa implementasi muatan nilainilai SPBS dalam akun pemerintah pusat yaitu akun Facebook Humas Setda Sumedang dan Instagram@humas_sumedang yang belum sesua rekomendasi.

Rekomendasi lainnya dalam mengelola media sosial adalah dengan memahami target audiens serta merancang kota yang bisa melibatkan audiens tadi dengan sentuhan manusiawi. Selain itu mencontoh akun media sosial Place Branding lainnya yang lebih maju bisa menjadi acuan dalam publikasi konten media sosial. Sebaiknya publikasi yang dilakukan dalam website turut melibatkan komunitas serta masyarakat sebagai wakil-wakil humas di luar organisasi, apalagi pemkab Sumedang memiliki rekan kerja dalam pelaksanaan SPBS yaitu Dewan
Kebudayaan Masyarakat.

Langkah terakhir dalam implementasi brand vision adalah logistik. Logistik sendiri berkaitan dengan kapabilitas organisasi untuk mencapai tujuan yang ada di masa sekarang dan masa depan serta kaitannya dengan sumber daya yang ada. Singkat kata logistik brand adalah langkah yang ditempuh untuk mengkomunikasikan, meningkatkan, dan mengevaluasi brand identity yang terbangun.

Logistik brand SPBS sendiri erat kaitannya dengan jumlah resource atau staff yang memiliki atau menjalankan tugas komunikasi dalam Place Branding SPBS. Adapun dalam pelaksanaanya jumlah staff yang memegang peran komunikasi dalam Place Branding SPBS mencapai 3-5 orang, jumlah yang cukup sedikit karena memang tidak ada departemen atau divisi khusus yang menangani SPBS karena ranahannya yang cukup implementatif dan bisa menjadi fungsi bagi beberapa departemen seperti Humas Setda Sumedang, Disparpora Kabupaten Sumedang, dan Bappeda Sumedang.

Menurut Zavattaro, lebih baik menggunakan staf fyang sedikit tapi optimal sehingga bisa menyampaikkan pesan seara tepat dan cepat. Jika jumlah sumber daya yang dialokasikan dalam perancangan program Place Branding sedikit maka fokus utama seharusnya dalam menyampaikan informasi dengan cara yang cepat dan mudah, selain itu penggunaan tolok ukur dan evaluasi pun harus ditentukan bagi orang yang bertugas dalam posisi ini (Hankinson, 2009)

Selanjutnya pada tahap terakhir yaitu tahap evaluasi brand equity Sumedang Puseur Budaya Sunda. Menurut Zavattaro (2014:122) ada dua langkah yang harus ditempuh dalam proses implementasi brand ini, yaitu (1) Implementing or refining success measures, dan (2) course correct. 


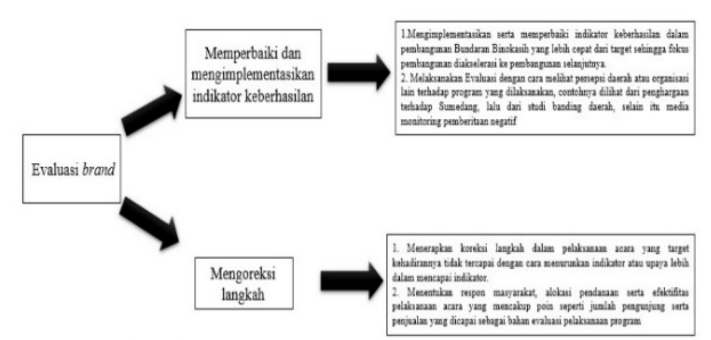

\section{Gambar 5. Tahapan proses evaluasi Brand}

Langkah pertama dalam implementing or refining success measures adalah mengimplementasikan serta memperbaiki indikator keberhasilan ketika indikator keberhasilan suatu program tercapai dengan gemilang. Adapun penerapannya di pemkab Sumedang, yaitu misalnya dalam pembangunan Bunderan Binokasih yang ditargetkan selesai di tahun 2018 tapi sudah selesai di tahun 2016 maka ada percepatan pembangunan ke target selanjutnya

Tahap selanjutnya yaitu implementasi evaluasi dalam SPBS dilakukan dengan cara dilihat dari persepsi daerah atau organisasi lain terhadap program yang dilaksanakan, contohnya dilihat dari penghargaan yang didapatkan pemkab Sumedang, lalu dari studi banding daerah-daerah yang cukup banyak ke Sumedang ${ }^{4}$. Selain itu, evaluasi secara media menggunakan media monitoring yang memonitor publikasi media terutama yang bersifat negatif. Selanjutnya dari pemberitaan negatif tadi akan dibuat sebuah rekomendasi tindakan yang akan disampaikan pada dinas terkait yang dalam konteks SPBS adalah Disparpora. ${ }^{5}$

Pemkab Sumedang hanya menentukan tujuan dalam sudut pandang pemkab dan belum mampu mempertimbangkan pemangku kepentingan lainnya, misalnya dalam perancangan tujuan yang hanya terfokus pada aparatur pemerintahan dan Disparpora serta

\footnotetext{
${ }^{4}$ Hasil Wawancara dengan Ade Rohana, selaku Kepala Bidang Kebudayaan Disp/arpora Sumedang, pada 16 Mei 2018 di Kantor Disparpora Kabupaten Sumedang.
}

dinas pemerintahan lainnya. Hal ini belum sesuai dengan rekomendasi lainnya yaitu dalam indikator keberhasilan turut menarget pemangku kepentingan, misalnya bagi penduduk, pengunjung, bisnis serta industri.

Selanjutnya, evaluasi dalam SPBS dilakukan dengan cara melihat persepsi daerah atau organisasi lain terhadap program yang dilaksanakan, contohnya dilihat dari penghargaan terhadap Sumedang, lalu dari studi banding daerah, selain itu media monitoring pemberitaan negatif dan upaya ini telah sesuai dengan rekomendasi. (Zavattaro, 2014:150).

Memang dalam penerapan evaluasi pada Place Branding, salah satu metode yang paling sering digunakan adalah kliping media atau indikator kunjungan wisatawan karena keterbatasan media untuk metode lainnya yang lebih mahal (Zenker \& Seigis, 2012:35). Akan tetapi sebaiknya media monitoring pun dilakukan tidak hanya dalam bentuk kliping media atau media cetak saja namun termasuk media monitoring secara.

Tahap selanjutnya yaitu course correct, atau koreksi langkah yang merupakan tahap yang ditempuh saat indikator suatu perancangan tidak dapat tercapai. Langkah pertama adalah dalam implementasi ketika indikator keberhasilan suatu taktik tidak tercapai. Adapun implementasi dalam pelaksanaan program SPBS pemkab Sumedang adalah misalnya dalam pelaksanaan acara yang capaian kehadirannya tidak tercapai, maka akan ada penyesuaian dalam kelengkapan logistik dan konsumsi acara tersebut dalam perancangan kedepannya.

Langkah selanjutnya adalah dengan menentukan apa saja bahan yang digunakan untuk evaluasi dalam pelaksanaan kegiatan. Adapun implementasi dalam SPBS adalah berasal dari animo masyarakat terhadap pelaksanaan suatu acara, akan tetapi untuk

\footnotetext{
${ }^{5}$ Hasil Wawancara dengan Wahyu Kusdiarto, selaku Kepala Sub Bagian Pemberitaan dan Dokumentasi Setda Kabupaten Sumedang, pada 11 Mei 2018 di KantorSetda Sumedang.
} 
pelaksanaan perbup biasanya masih di tingkat internal pemerintahan dengan masukan dari pimpinan atau rekanan dinas tanpa adanya riset formal.

Seharusnya pemkab Sumedang turut memperhatikan ekspektasi serta kepuasan para pemangku kepentingan yang vital demi memastikan infrastruktur merek sudah kuat dan mendukung pelaksanaan Place Branding, Karena itu, langkah yang seharusnya dilakukan adalah melibatkan pemangku kepentingan guna mendapatkan pemahaman yang lebih tentang masalah ini (Hanna \& Rowley, 2011:464). Hal inilah yang mesti diimplementasikan pula dalam evaluasi kebijakan pada level aparatur pemerintahan serta pemangku kepentingan yang ikut terpengaruh sehingga mampu mengidentifikasi permasalahan yang penting dan langkah implementasi yang tepat guna menanggapinya

Salah satu pendekatan yang dapat diaplikasikan dalam Place Branding SPBS adalah dengan pendekatan yang lebih berpusat pada kepuasan konsumen, adapun metode yang dapat digunakan seperti melalui wawancara langsung terhadap orang di jalan, penyebaran angket pengunjung, atau penggunaan hashtag pada media sosial yang akan memudahkan evaluasi secara online (Yoo \& Donthu, 2000).

Rekomendasi terkait praktek balancing image through substance yang dirancang oleh Zavattaro adalah dengan menggunakan evaluasi secara finansial dan evaluasi secara basis konsumen, yang pada akhirnya akan menentukan apakah pemasukan meningkat atau apakah wisatawan merekomendasikan tempat yang ia kunjungi pada orang lain, jika yang satu fokus pada penjualan maka yang lainnya fokus pada pemasaran (Zavattaro, 2014:151). Sayangnya dalam pelaksanaanya evaluasi yang dilakukan oleh Pemkab Sumedang terkesan masih berkutat pada jaringan internal serta evaluasi pada permasalahan yang tidak begitu signifikan, hal ini tersirat pada upaya evaluasi sendiri yang tidak diagendakan serta pemahaman atas metode evaluasi yang memenuhi standar oleh pemkab Sumedang.

\section{SIMPULAN}

Secara garis besar, program Place Branding Sumedang sebagai Puseur Budaya Sumedang sudah sesuai dengan langkahlangkah dalam konsep Place Branding milik Zavattaro. Dari mulai analisisa SWOT, menciptakan brand vision, menetapkan goals dan benchmarks, mengimplementasikan brand vision dan proses evaluasi brand equity.

Hasil yang diperoleh pada tahap penciptaan brand vision meliputi dua bagian yaitu identify and create core value, dan create brand vision. Adapun untuk tahap identify and create core value, nilai inti dari Place Branding SPBS dalam tingkat filosofis yaitu Insun Medal, Insun Madangan, lalu nilai operasionalnya sesuai dengan Perbup No. 113 Tahun 2009.

Hasil dari tahap menentukan program goals dan benchmarks meliputi dua bagian yaitu set program goals dan establish benchmarks. Pada bagian set program goals, capaian dari program Place Branding SPBS adalah penguatan identitas aparatur pemerintahan dan meningkatkan daya saing daerah yang belum bisa terkunatifikasi dengan baik. Selanjutnya dalam bagian establish benchmarks, hasilnya SPBS tidak memiliki acuan atau tinjauan daerah khusus dalam mengukur keberhasilan, meskipun SPBS turut mempertimbangkan kekuatan internal pula dalam pelaksanaan

Hasil dari tahap implementasi brand vision meliputi tiga bagian yaitu brand communication, brand expansion, dan Logistik. Pada bagian brand communication, bentuk komunikasi internal SPBS secara Primer, rapat-rapat sosialisasi kebijakan dan Sekunder, pakaian dinas, majalah internal, lagu, lalu saluran komunikasi internal SPBS adalah melalui saluran Formal, Rapat koordinasi, sosialisasi kebijakan dan Informal, silaturahmi, lagu, majalah internal, seragam respon dari pihak internal cukup 
baik namun dalam implementasi kebijakan masih belum dilaksanakan oleh segenap internal, lalu Bentuk pengkomunikasian eksternal SPBS adalah Antarpersonal melalui tayangan iklan, talkshow, liputan acara, sosmed dan media luar ruang, sedangkan Saluran komunikasi eksternal SPBS adalah informal melalui tayangan iklan, talkshow, lagu dan media luar ruang, kebijakan ini masih dirasa kurang karena belum bisa mendapatkan aksi dari audiensnya. Selanjutnya pada tahap logistik, pemkab Sumedang belum merancang prosedur komunikasi staff komunikasi SPBS padahal jumlahnya cukup sedikit dan perlu SOP agar kinerjanya semakin cepat dan tepat.

Hasil dari tahap evaluasi brand meliputi dua bagian yaitu implementing or refining success measures dan course correct, pada tahap implementing or refining success measures. Pada tahap pertama yaitu implementasi atau perbaikan ukuran kesuksesan. Pemkab Sumedang masih menyisakan ruang untuk perbaikan seperti penerapannya dalam pelaksanaan acara sehingga mampu meningkatkan tingkat ketercapaian indikator keberhasilan dan menurunkan resiko kegagalan perencanaan, lalu evaluasi dalam SPBS dilakukan dengan cara melihat persepsi daerah atau organisasi lain terhadap program yang dilaksanakan misalnya dilihat dari penghargaan pemerintah, studi banding daerah, serta media monitoring.

\section{Daftar Pustaka}

Aaker, David. 1991. Managing Brand Equity. Detroit: Free Press

Doran, George. 1981. There's a S.M.A.R.T. Way to Write Management's Goals and Objectives. Management Review, 70, 35-36.

Goldhaber, G. \& Krivonos, P. 1977. "The ICA Communication Audit: Process, status, critique" Journal of Business Communication, 15(1), 41-55

Hanna, S. \& Rowley,, J. 2013. "Place brand;s practitioners' perspectives on the management and evaluation of the brand experience" Town Planning Review. 84(4), 474-493.

Hankinson, G. Managing destination brands: establishing a theoritical foundation. Journal of Marketing Management. 2009. Vol. 25, No. 1-2, pp. 97115.

Isberg, S. \& Pitta, D. 2013. "Using financial analysis to assess brand equity". Journal of Place Management and Development, 22 (1), 65-78

Mathieu, JE. 2005. Scaling the Quality of Teammates mental models: Equifinality and Normative Comparisons. Journal of Organizational Behavior. Vol 26, Issue 1

Nugraha, Aat R., Komariah, Kokom. \& Subekti, Priyo. Fungsi Humas Pemerintah Kabupaten

Sumedang Dalam Mengkampanyekan Sumedang Sebagai Puseur Budaya Sunda (SPBS). Edutech, Tahun 13, Vol.1, No.1, Februari 2014

Reynolds, D. B. \& Phillips, C. A. 2003. Modelling the Dynamic Characteristics of Pneumatic Muscle. Annals of Biomedical Engineering. March 2003, Vol. 31, Issue 3 pp 310317

Sugiyono. 2012. Metode Penelitian Kuantitatif Kualitatif dan R\&D. Bandung:Alfabeta

Spiggle, Susan (2012) More Than Fit: Brand Extension Authencity.

Yoo, B. \& Donthu, N. 2001. "Developing and validating a multidimensional consumer-based brand equity scale." Journal of Bussiness Research, 52(1), 1-14.

Zavattaro, Staci. 2014. Place Branding Through Phases of The Image: Balancing Image and Substance. London: Palgrave Macmillan.

Zenker, S. \& Martin, N. 2009. "Measuring Success in place marketing and branding". Place Branding \& Public Diplomacy, 7(1), 32-41 